\title{
Withaferin A attenuates Alcohol Abstinence Signs in Rats
}

\author{
Nandkishor Ramdas Kotagale, Ankit Kedia, Rupali Gite, Shubham Nilkanth Rahmatkar, Dinesh Yugraj Gawande, \\ Milind Janraoji Umekar, Brijesh Gulabrao Taksande*
}

\section{Nandkishor Ramdas Ko- tagale, Ankit Kedia, Rupali Gite, Shubham Nilkanth Rahmatkar, Dinesh Yugraj Gawande, Milind Janraoji Umekar, Brijesh Gulabrao Taksande}

Department of Pharmacology, Division of Neuroscience, Shrimati Kishoritai Bhoyar College of Pharmacy, New Kamptee, Nagpur, Maharashtra, INDIA.

Correspondence

Brijesh Gulabrao Taksande

Division of Neuroscience, Department of Pharmacology, Shrimati Kishoritai Bhoyar College of Pharmacy, New Kamptee,

Nagpur, Maharashtra, INDIA.

Phone no. +91-7109-288650,

Fax No. +91-7109-287094

E-mail: brijeshtaksande@gmail.com

History

- Submission Date: 11-12-2017;

- Review completed: 03-05-2018;

- Accepted Date: 06-08-2018

DOI : 10.5530/pj.2018.6.204

Article Available online

http://www.phcogj.com/v10/i6

Copyright

(C) 2018 Phcog.Net. This is an openaccess article distributed under the terms of the Creative Commons Attribution 4.0 International license.

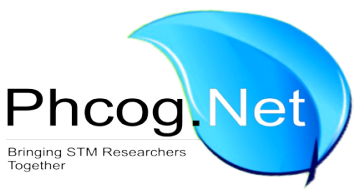

\begin{abstract}
Background: Withania somnifera (WS) have been reported to inhibit acquisition and expression conditioned place preference, self-administration and withdrawal anxiety of psychostimulants. In the present work, we have assessed the effect of Withaferin A on somatic and affective symptoms of ethanol withdrawal syndrome in rats. Methods: Animals had given free access to ethanol uninterrupted for 21 days through liquid diet. Withaferin A $(5,10$ and $20 \mathrm{mg} / \mathrm{kg}$ ) was injected (ip) either during the development of ethanol dependence phase (days $15-21$ or 30 min before ethanol withdrawal assessment. Withdrawal signs characterized by changes in somatic signs were measured in the open field followed by evaluation of anxiety parameters, locomotion, and depressive behavior. Results: Withaferin A treatment 30 min before $24 \mathrm{~h}$ postethanol withdrawal assessment did not alter the scores of somatic behavioral signs in ethanol abstinence animals. However, withaferin A (10 and $20 \mathrm{mg} / \mathrm{kg}$, ip) from day 15-21 prevented the ethanol withdrawal-induced elevated scores of somatic behaviors, hyperlocomotion, depressive behavior, and anxiety. Withaferin A treatment did not influence the blood ethanol levels in dependent and withdrawn animals. However, withaferin A administration attenuated the elevated plasma corticosterone and ACTH levels in ethanol-withdrawn rats, suggesting withaferin A induced anti-stress effect and stabilization of HPA axis activity could have facilitated the inhibitory effect of withaferin A on ethanol withdrawal syndrome. Conclusion: The finding supports further investigation of Withaferin A and other bioactive components of WS in alcohol addiction.

Key words: Anxiety, Corticosterone, Ethanol withdrawal, HPA axis, Withaferin A.
\end{abstract}

\section{INTRODUCTION}

Alcohol withdrawal syndrome is potentially lifethreatening in addicted people and associated maladies constitute a serious health and social issues. ${ }^{1}$ Abstinence from chronic ethanol consumption leads to the manifestation of a variety of somatic and affective symptoms attributed to central nervous system hyperexcitability, like irritability, anxiety, restlessness and dysphoria. ${ }^{2}$ Despite the tremendous advances made in the treatment of alcoholism and/or its abstinence, remarkably, the majority of these agents, including naltrexone and benzodiazepines etc. have unpleasant side effect. ${ }^{3,4}$

Withaferin A is a steroidal lactone, an active compound isolated from Withania somnifera (WS) (Family- Solanaceae). WS, known as ashwagandha in Ayurveda or its active principles, including withaferin A has been used as an antioxidant, adaptogen, antistress, ${ }^{5,6}$ anti-inflammatory, neuroprotective, anxiolytic, antidepressant, immunomodulatory, memory enhancer, anti-ulcer and anti-carcinogenic agents. ${ }^{7-12}$ In addition, WS extract has been inhibited the morphine-induced acquisition and expression in conditioned place preference, ${ }^{13}$ ethanol conditioned place preference ${ }^{14}$ and self-administration, ${ }^{15}$ ethanol withdrawal-induced anxiety in rats. ${ }^{16}$ In the present work, we have assessed the effect of withaferin A on somatic and affective symptoms of ethanol withdrawal syndrome in rats.

\section{MATERIALS AND METHODS}

\section{Subjects}

Adult healthy Sprague Dawley rats weighing 200-220 g (3-4 months old) were group housed (four per cage) under controlled temperature $\left(25 \pm 2^{\circ} \mathrm{C}\right)$ and light $(12 \mathrm{~h}$ light/dark cycle, light on at $07.00 \mathrm{am}$ ) environment with free access to food and water. Experimental protocols were approved by the Institutional Animal Ethical Committee and executed in strict accordance with the guidelines of Committee for the Purpose of Control and Supervision of Experiments on Animals, Govt. of India. The behavioral assessments were conducted during the light cycle.

\section{Drugs}

Withaferin A was purchased from Natural Remedies Private Limited, Bangalore, India and administered intraperitoneally (ip) as a solution $(1 \mathrm{ml} / \mathrm{kg})$ in dimethylsulphoxide (DMSO) prepared just before the experiments. Ethanol (99\% w/v) (Merck, India) 
was given through liquid diet. Doses and timing of the drug injections with respect to the behavioral testing employed in the protocols were selected on the basis of previous experiments carried in our laboratory and available literature. ${ }^{17,18}$

\section{Induction of ethanol dependence and withdrawal}

All different groups of rats $(n=16-20)$ housed individually were given free access to nutritionally balanced liquid diet (Novartis India Ltd., Mumbai) without ethanol for 7 days to allow adaptation to the novel food. Water was made freely available. From $8^{\text {th }}$ day onwards, half of the animals $(\mathrm{n}=6)$ had given free access to ethanol uninterrupted for 21 days through liquid diet. ${ }^{19}$ Initially, $2.4 \% \mathrm{v} / \mathrm{v}$ ethanol was introduced into the liquid diet for 3 days, which was increased to $4.8 \% \mathrm{v} / \mathrm{v}$ for the following 4 days and finally to $7.2 \% \mathrm{v} / \mathrm{v}$ for 14 days (ethanol-fed group). The remaining rats kept on the control liquid diet (nutritionally balanced) (pair-fed group). Every day fresh ethanol and control liquid diet $(100 \mathrm{ml} / \mathrm{rat})$ was introduced into the cage each morning at $0900 \mathrm{~h}$. The weight of each rat was recorded everyday and daily ethanol intake was monitored and expressed as g/kg/day. From day 22 (0900 h), pair-fed groups were continued on the same diet, whereas to ethanol-fed groups, ethanol diet was stopped and animals were fed with isocaloric liquid diet (without ethanol) until the end experiment. Control rats $(n=6)$ were pair-fed with an isocaloric liquid diet containing sucrose as a caloric substitute to ethanol.

This protocol had two segments: In the first design, withaferin A $(5,10$ and $20 \mathrm{mg} / \mathrm{kg}$ ) was injected (ip) during the development of ethanol dependence phase (days 15 - 21). In the second design,withaferin $A$ $(5,10$ and $20 \mathrm{mg} / \mathrm{kg}$ ) was administered to rats $30 \mathrm{~min}$ before ethanol withdrawal assessment. Separate groups $(n=6)$ of rats were assigned to different doses. Appropriate vehicle-treated controls were also maintained simultaneously.

\section{Behavioral changes during ethanol withdrawal}

At $24 \mathrm{~h}$ post ethanol withdrawal, the pair-fed groups, as well as ethanol-fed groups, were subjected to evaluation of ethanol withdrawal syndrome. This time point was selected since peak withdrawal somatic and affective signs were apparent at this time point. ${ }^{17,18,20,21}$ Withdrawal signs characterized by changes in somatic signs were measured in open field for $15 \mathrm{~min} .{ }^{19}$ This was followed by evaluation of anxiety parameters in elevated plus maze (EPM), ${ }^{18}$ locomotion (actophotometer) and depressive behavior (Porsolt's forced swim test, FST) each for 5 min duration. ${ }^{17}$ All the animal experiments were performed during the light cycle between 0900 and $1200 \mathrm{~h}$.

\section{Somatic signs}

At $24 \mathrm{~h}$ of ethanol withdrawal, animals were observed individually for $15 \mathrm{~min}$ and the frequency of various stereotyped behavioral signs that included grooming, sniffing, head weaving, gnawing, chewing, scratching, genital licking and body shake were recorded. Ethanol abstinence score (EAS) consisting of the sum of all the stereotyped behaviors was compiled and expressed as mean \pm SEM. ${ }^{22}$ Wet dog shakes, tremors, tail stiffness, abnormal gait and posture, abdominal constriction and teeth chattering were also assessed for the incident.

\section{Anxiety related behavior}

The anxiety in animals was evaluated in elevated plus maze (EPM), the earlier reported experimental protocol was followed. ${ }^{18}$ Briefly, after $24 \mathrm{~h}$ of withdrawal rats were placed on the central platform of EPM with open arm facing. In EPM following variables were recorded during $5 \mathrm{~min}$, frequencies and time spent in closed and open arms respectively. After each test, the platform of the maze was wiped and cleaned with damp cotton. All subjects were experimentally naive at the beginning of each study and used only once to avoid 'one trial tolerance' to EPM test.

\section{Locomotor activity}

Locomotor activities of the rats were recorded by an automatic actophotometer $(38 \times 38 \times 14 \mathrm{~cm})$ (VJ instruments, Karanja, India). Any movement of the rat that interrupted photo beams was recorded as a total of horizontal, vertical and ambulatory activities and expressed as mean motor counts \pm SEM. Locomotor counts were not recorded for first 5 min after placement and the spontaneous locomotor count of each animal was recorded for following $5 \mathrm{~min}$. After each animal's recording, the grid floor of actophotometer was carefully cleaned. The data are expressed as a mean number of counts for $5 \mathrm{~min}$.

\section{Depressive behavior}

Porsolt's forced swim test (FST) was used to determine the depressive behavior in ethanol-withdrawal rats. ${ }^{23-24}$ Animals were individually allowed for forced to swim in a cylindrical glass tank $(46 \mathrm{~cm} \times 20 \mathrm{~cm})$ containing $30 \mathrm{~cm}$ of water and the time of immobility was recorded. Two swimming sessions were carried out with an initial 15 min 'pre-test' followed by a 6 min test after $24 \mathrm{~h}$. Reduction in the duration of immobility was considered as attenuation of the depressive behavior of ethanol withdrawal. A trained observer blind to the treatments monitored the immobility time, which is the measure of depression.

\section{Determination of blood ethanol, corticosterone and ACTH levels}

Blood samples were collected from a separate group of animals at $1 \mathrm{~h}$ before $(0800 \mathrm{~h})$ and at $24 \mathrm{~h}$ after $(0900 \mathrm{~h})$ ethanol withdrawal from a rat tail vein in heparinized tubes and centrifuged at $13000 \times \mathrm{g}$ for 15 $\min$ at $4^{\circ} \mathrm{C}$ to separate plasma and stored at $-20^{\circ} \mathrm{C}$. The separated plasma samples were then used to determine ethanol, corticosterone and adreno-corticotropic hormone (ACTH).Plasma ethanol concentrations were determined by nicotinamide adenine dinucleotide-alcohol dehydrogenase enzymatic assay (Sigma-Aldrich, St. Louis, MO, USA). ${ }^{25}$ Plasma corticosterone concentrations were measured using a quaternary gradient HPLC system equipped with a Crestpak C18T-5 column and PDA detector (MD2010 plus) (Jasco, Japan) as per the earlier described procedure. ${ }^{26,27} \mathrm{ACTH}$ concentrations in plasma were measured by twosite ELISA assay using a commercial kit (Sigma-Aldrich, St. Louis, MO, USA). ${ }^{28}$

\section{Data Analysis}

The results are presented as mean \pm SEM. The data obtained from ethanol-withdrawal and pair-fed rats were compared by unpaired t-test. The effects of different acute drug treatments were statistically analyzed by one-way analysis of variance (ANOVA) followed by post hoc Dunnett's test or Bonferroni multiple comparison tests. A value of $P<0.05$ was considered significant.

\section{RESULTS}

\section{Ethanol consumption, body weight, and ethanol levels}

Daily ethanol consumption of the rats in ethanol-fed control and withaferin A treated groups ranged from $13.6 \pm 1.3$ to $15.8 \pm 2.1 \mathrm{~g} / \mathrm{kg}$ during exposure to ethanol $(7.2 \% \mathrm{w} / \mathrm{v})$ of last 2 weeks. However, this difference was not statistically significant. Average liquid food consumption of the above two groups was $42.5 \pm 4.2$ and $44.3 \pm 6.1 \mathrm{ml} /$ rat from day $1-21$ and was not different from the pair-fed control animals.

On the $21^{\text {st }}$ day of the experiment, the mean body weight of pair-fed and ethanol-fed animals were $207.2 \pm 4.9 \mathrm{~g}$ (against the average body weight 
of $204.3 \pm 3.5 \mathrm{~g}$ on day 1 ) and $208.5 \pm 3.8 \mathrm{~g}$ (against the average body weight of $211.6 \pm 6.8 \mathrm{~g}$ on day 1 ) respectively and these body weight changes in pair-fed and ethanol-fed animals were statistically insignificant. Blood ethanol concentration was found to be $173.79 \pm 7.68 \mathrm{mg} / \mathrm{dl}$ and $6.31 \pm 0.99 \mathrm{mg} / \mathrm{ml}, 1 \mathrm{~h}$ before $(0800 \mathrm{~h})$ and at $24 \mathrm{~h}$ after $(0900 \mathrm{~h})$ ethanol withdrawal respectively (Table 1 ). The decreased blood ethanol level $24 \mathrm{~h}$ after withdrawal was found significantly correlated with the abstinence signs.

\section{Behavioral changes during ethanol withdrawal}

The significant stereotyped behaviors (somatic behaviors) such as grooming $(\mathrm{t}=3.055, \mathrm{df}=2, \mathrm{P}=0.0185)$, scratching $(\mathrm{t}=4.085, \mathrm{df}=2$, $\mathrm{P}=0.0047)$, head shake $(\mathrm{t}=3.705, \mathrm{df}=2, \mathrm{P}=0.0076)$, genital licking $(\mathrm{t}=3.831, \mathrm{df}=2, \mathrm{P}=0.0064)$, chewing $(\mathrm{t}=3.055, \mathrm{df}=2, \mathrm{P}=0.0185)$, body shakes $(\mathrm{t}=3.020, \mathrm{df}=2, \mathrm{P}=0.0194)$ etc. were evident in ethanol dependent rats when compared with control pair fed animals at $24 \mathrm{~h}$ post withdrawal. The sum of all the stereotyped behaviors expressed as EAS was significantly higher in ethanol withdrawn rats as compared to pair fed animals $(\mathrm{t}=3.49, \mathrm{df}=10, \mathrm{P}<0.01$; unpaired $\mathrm{t}$ test) (Figure 1 ). However, tail stiffness, abnormal gait, abnormal posture, abdominal constriction, wet dog shakes, tremor or teeth chattering were not observed in the withdrawn, pair fed as well as treated animals.

\begin{tabular}{|c|c|c|}
\hline \multirow{2}{*}{ Treatment groups } & \multicolumn{2}{|c|}{ Blood ethanol concentration (mg/dl) } \\
\hline & Before withdrawal & $24 \mathrm{~h}$ after withdrawal \\
\hline Vehicle (1 ml/kg, ip) & $173.79 \pm 7.68$ & $6.31 \pm 0.99$ \\
\hline Withaferin A (5 mg/kg, ip) & $169.32 \pm 6.73$ & $5.44 \pm 0.71$ \\
\hline Withaferin A (10 mg/kg, ip) & $174.44 \pm 8.15$ & $7.86 \pm 0.84$ \\
\hline Withaferin A (20 mg/kg, ip) & $170.79 \pm 7.08$ & $6.76 \pm 0.81$ \\
\hline
\end{tabular}

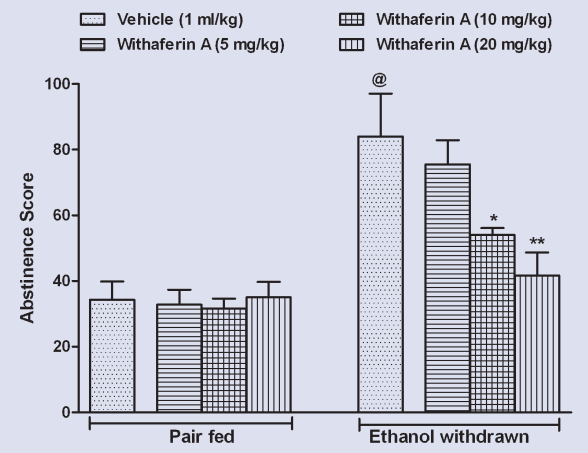

Figure 1: Effect of withaferin A on ethanol withdrawal-induced somatic behaviors. Rats were given free access to ethanol through liquid modified diet for of 21 days and from the $22^{\text {nd }}$ day onwards they were deprived of ethanol. Animals were treated with withaferin A (5-20 mg/kg, ip) once daily from day $15-21$ of ethanol dependence. Somatic behaviors (grooming, jumping, genital licking, leg licking, head shakes etc.) were determined for $15 \mathrm{~min}$ at $24 \mathrm{~h}$ following ethanol withdrawal. Each bar indicates mean EAS \pm SEM $(n=6)$. @P $<0.001$ vs vehicle-treatedpair-fed rats; ${ }^{*} P<0.05,{ }^{*} P<0.01$ vs vehicle-treatedethanol-withdrawn animals (One way ANOVA post hoc Bonferroni test).

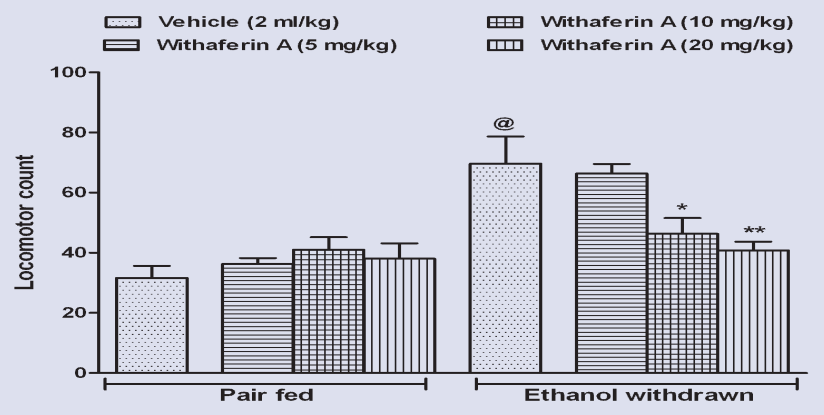

Figure 2: Effect of withaferin A on ethanol withdrawal-induced locomotor hyperactivity. Rats were given free access to ethanol through liquid modified diet for 21 days and from the $22^{\text {nd }}$ day onwards they were deprived of ethanol. Animals were treated with withaferin A (5 - $20 \mathrm{mg} /$ $\mathrm{kg}$, ip) once daily from day $15-21$ of ethanol dependance. Locomotor activity was determined for $5 \mathrm{~min}$ in actophotometer at $24 \mathrm{~h}$ following ethanol withdrawal. Each bar indicates mean locomotor counts \pm SEM $(\mathrm{n}=6)$. @P $<0.01$ vs vehicle-treated pair-fed rats; ${ }^{*} P<0.05,{ }^{* *} P<0.01$ vs vehicle-treated ethanol-withdrawn animals (One way ANOVA post hoc Bonferroni test).

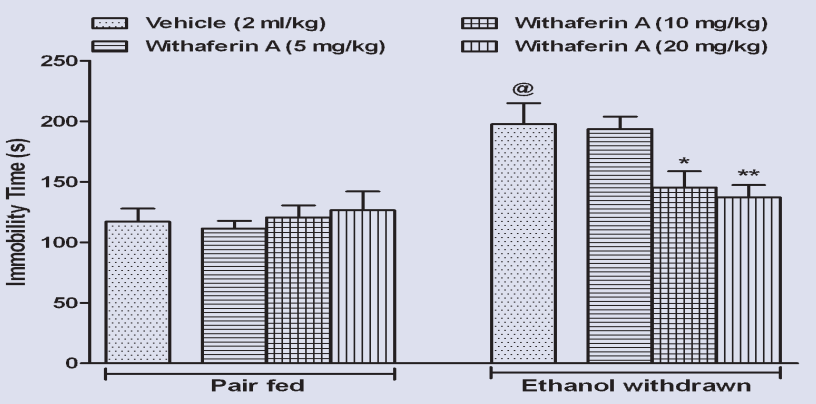

Figure 3: Effect of withaferin A on ethanol withdrawal-induceddepressive behaviors. Rats were given free access to ethanol through liquid modified diet for of 21 days and from the $22^{\text {nd }}$ day onwards they were deprived of ethanol. Animals were treated with withaferin A (5 - 20 $\mathrm{mg} / \mathrm{kg}$, ip) once daily from day $15-21$ of ethanol dependence. Immobility duration was determined for $5 \mathrm{~min}$ in FST at $24 \mathrm{~h}$ following ethanol withdrawal. Each bar indicates mean immobility time (s) \pm SEM $(n=6)$. $@ \mathrm{P}<0.01$ vs vehicle-treated pair-fed rats; ${ }^{*} \mathrm{P}<0.05$, ${ }^{* *} \mathrm{P}<0.01$ vs vehicletreated ethanol-withdrawn animals (One way ANOVA post hoc Bonferroni test).

A significant locomotor hyperactivity was observed in ethanol-withdrawal animals at the $24 \mathrm{~h}$ of post-withdrawal testing as compared to control animals $(\mathrm{t}=3.86, \mathrm{df}=10, P<0.01$; unpaired $\mathrm{t}$-test) (Figure 2). Similarly, when tested in FST, immobility time was increased as compared to pair-fed animals $(\mathrm{t}=3.93, \mathrm{df}=10, P<0.01$; unpaired $t$-test $)$ (Figure 3).

As depicted in Figure 4, animals withdrawn from the chronic ethanol exhibited the anxiogenic effect indicated by animal behavior in the maze. Significant decrease in \% time spent in open arm $(\mathrm{t}=5.49, \mathrm{df}=10$, $P<0.001$; unpaired $t$-test $)$ and $\%$ open arm entries $(\mathrm{t}=3.84, \mathrm{df}=10$, 


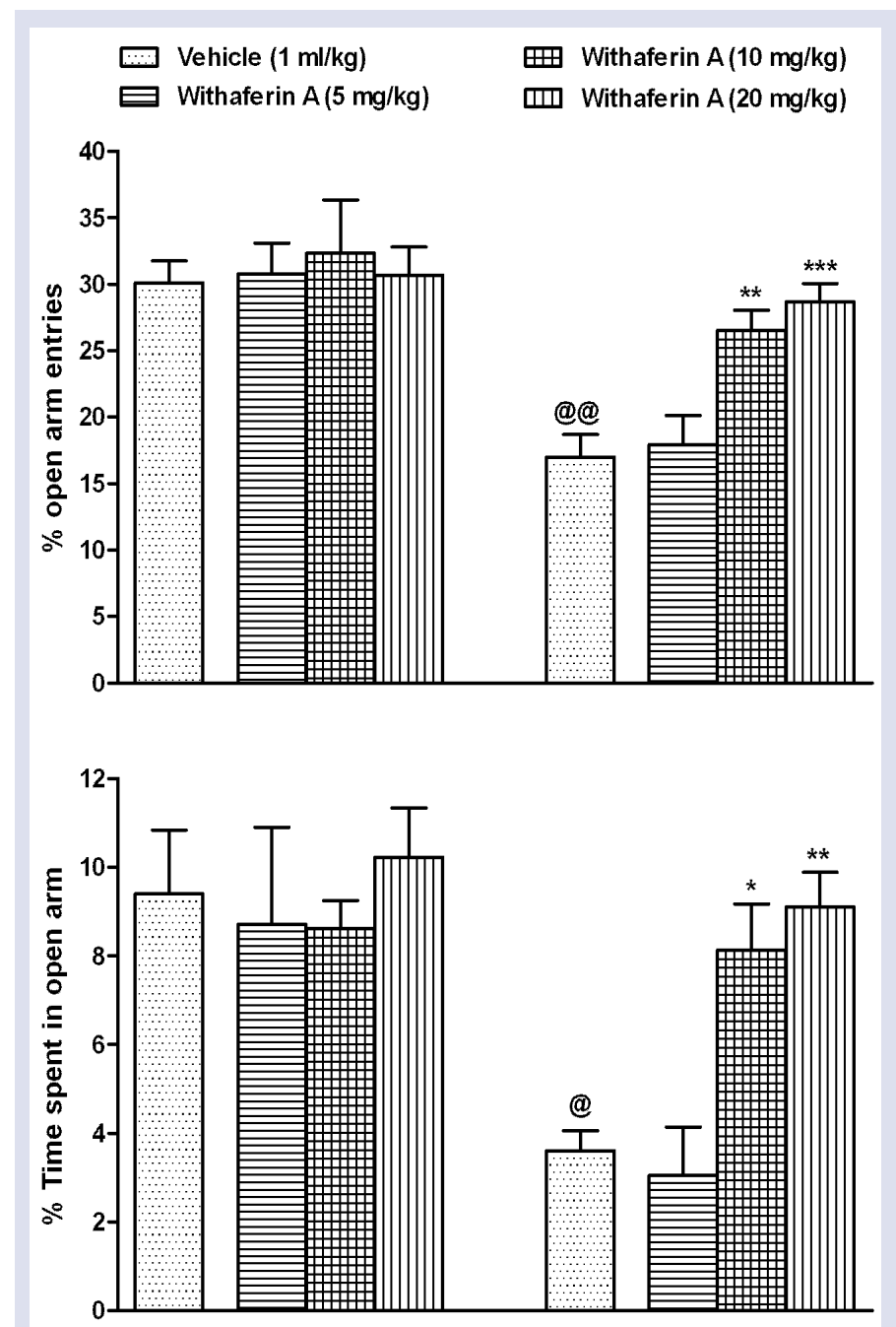

Figure 4: Effect of withaferin A on ethanol withdrawal-inducedanxietyrelated behaviors. Rats were given free access to ethanol through liquid modified diet for of 21 days and from the $22^{\text {nd }}$ day onwards they were deprived of ethanol. Animals were treated with withaferin A ( $5-20 \mathrm{mg} / \mathrm{kg}, \mathrm{ip})$ once daily from day $15-21$ of ethanol dependance. The number of entries (A)and time spent (B) were determined for $5 \mathrm{~min}$ in EPM at $24 \mathrm{~h}$ following ethanol withdrawal. Each bar indicates mean $\%$ entries/time spent in open arm \pm SEM $(n=6)$. @P $<0.001$ vs vehicle-treatedpair-fed rats; ${ }^{*} P<0.05$, ${ }^{* * P}$ $<0.01$, ${ }^{* * *} \mathrm{P}<0.001$ vs vehicle-treatedethanol-withdrawn animals (One way ANOVA post hoc Bonferroni test).

$P<0.01$; unpaired $t$-test) was observed in ethanol-withdrawn rats when compared with pair-fed group.

\section{Withaferin A attenuates ethanol withdrawal-induced behaviors}

Withaferin A (5 - $20 \mathrm{mg} / \mathrm{kg}$, ip) treatment $30 \mathrm{~min}$ before 24 h post-ethanol withdrawal assessment did not alter the scores of somatic behavioral signs in ethanol abstinence animals. Moreover, a single administration of withaferin A (5 - $20 \mathrm{mg} / \mathrm{kg}$, ip) before withdrawal assessment did not influence the locomotion, immobility time as well as EPM indices as compared to ethanol-withdrawn rats (Data not shown).

Chronic treatment with withaferin A (10 and $20 \mathrm{mg} / \mathrm{kg}$, ip) from day 15-21 significantly prevented the ethanol withdrawal induced elevated scores of somatic behaviors $[\mathrm{F}(4,29)=7.34 ; \mathrm{P}<0.001]$ (Figure 1) and hyperlocomotion $[\mathrm{F}(4,29)=9.46 ; \mathrm{P}<0.001]$ (Figure 2 ) as well as depressive behavior $[\mathrm{F}(4,29)=7.83 ; \mathrm{P}<0.001]$ (Figure 3). The posthoc Dunnett mean comparisons demonstrated that withaferin A (10 and $20 \mathrm{mg} / \mathrm{kg}$ ) treatment for 7 days in ethanol dependent rats significantly attenuated the elevated somatic scores $(\mathrm{P}<0.05$ and $\mathrm{P}<0.01)$, locomotor activity $(\mathrm{P}<0.05$ and $\mathrm{P}<0.01$ respectively $)$ and immobility time $(\mathrm{P}<0.05$ and $\mathrm{P}<0.01$ respectively) and when compared against vehicle treated ethanol withdrawn rats.

Similarly, as shown in Figure 4, ethanol-withdrawn rats treated with withaferin A (10 - $20 \mathrm{mg} / \mathrm{kg}$, ip) from day 15-21 along with ethanol exposure displayed a significant reduction in the withdrawal-induced anxiety as evident from decreased percent entries into the open arms $[\mathrm{F}(4,29)$ $=12.84 ; P<0.001]$ (Figure 4A) and percent time spent $[\mathrm{F}(4,29)=9.17$; $P<0.001$ ] (Figure $4 \mathrm{~B}$ ) as compared to ethanol-withdrawn rats administered with vehicle for 7 days. Post-hoc Dunnett analysis demonstrated a significant reversal of ethanol withdrawal-inducedanxiety behaviors [\% entries in open arm $(P<0.01$ and $P<0.01)$ and \% time spent in open arm $(P<0.05$ and $P<0.01)$ in animals treated with withaferin A $(10$ and $20 \mathrm{mg} / \mathrm{kg}$, respectively) in ethanol-dependentrats compared to vehicletreated controls. Administration of withaferin A in pair-fed animals did not alter basal somatic behaviors, immobility time, locomotor activity and plus-maze behaviors.

\section{Effect of withaferin A on ethanol withdrawal-induced elevated plasma ACTH and corticosterone levels}

As shown in Table 1, blood ethanol levels in withaferin A $(5-20 \mathrm{mg} / \mathrm{kg}$, ip) administered ethanol-withdrawn rats were not significantly different from vehicle-treated abstinence animals. However, as depicted in Table 2, ethanol withdrawal results in a significant elevation in plasma

Table 2: Plasma corticosterone concentration in withaferin A treated ethanol withdrawn rats. Separate groups of rats received ethanol in the liquid modified diet for 21 days and treated with withaferin $A(5-20 \mathrm{mg} / \mathrm{kg}$, ip) from day 15 - 21 of ethanol presentation. Plasma corticosterone concentration was measured $30 \mathrm{~min}$ before and $24 \mathrm{~h}$ after withdrawal. Data expressed as mean corticosterone level $(\mathrm{ng} / \mathrm{ml}) \pm \operatorname{SEM}(\mathrm{n}=6)$. \#P $<0.001$ vs vehicle treated ethanol fed rats $\mathbf{3 0}$ min before ethanol withdrawal, *P $<0.001$ vs vehicle treated ethanol fed rats $24 \mathrm{~h}$ after ethanol withdrawal.

\begin{tabular}{ccc}
\hline \multirow{2}{*}{ Treatment groups } & \multicolumn{2}{c}{ Plasma corticosterone concentration $(\mathrm{ng} / \mathrm{ml})$} \\
\cline { 2 - 3 } & Before withdrawal & 24 h after withdrawal \\
\hline Vehicle (1 ml/kg, ip) & $61.82 \pm 3.63$ & $166.8 \pm 15.91^{\sharp}$ \\
Withaferin A (5 mg/kg, ip) & $76.59 \pm 4.50$ & $140.4 \pm 8.35$ \\
Withaferin A (10 mg/kg, ip) & $74.93 \pm 6.31$ & $102.9 \pm 8.07^{\star}$ \\
Withaferin A (20 mg/kg, ip) & $75.02 \pm 7.89$ & $89.81 \pm 11.49^{*}$ \\
\hline
\end{tabular}

Table 3: Plasma ACTH concentration in Withaferin A treated ethanol withdrawn rats. Separate groups of rats received ethanol in the liquid modified diet for 21 days and treated with withaferin A (5-20 mg/kg, ip) from day $15-21$ of ethanol presentation. Plasma ACTH concentration was measured $24 \mathrm{~h}$ before and after withdrawal. Data expressed as mean ACTH level $(\mathrm{pg} / \mathrm{ml}) \pm S E M(n=6)$. \#P $<0.001$ vs vehicle treated ethanol fed rats 30 min before ethanol withdrawal, ${ }^{*} \mathrm{P}<0.05$ vs vehicle treated ethanol fed rats $24 \mathrm{~h}$ after ethanol withdrawal.

\begin{tabular}{ccc}
\hline \multirow{2}{*}{ Treatment groups } & \multicolumn{2}{c}{ Plasma ACTH concentration (pg/ml) } \\
\cline { 2 - 3 } & Before withdrawal & 24 h after withdrawal \\
\hline Vehicle (1 ml/kg, ip) & $122.2 \pm 13.82$ & $252.4 \pm 23.91^{*}$ \\
Withaferin A (5 mg/kg, ip) & $148.4 \pm 16.50$ & $205.2 \pm 35.78$ \\
Withaferin A (10 mg/kg, ip) & $140.7 \pm 15.31$ & $167.9 \pm 8.66^{*}$ \\
Withaferin A (20 mg/kg, ip) & $145.2 \pm 10.89$ & $164.3 \pm 15.07^{*}$ \\
\hline
\end{tabular}


corticosterone levels were as compared to their concentration before withdrawal $(\mathrm{t}=6.44, \mathrm{df}=10, P<0.001$; unpaired $t$-test). In order with the behavioral observations, Withaferin-A [10 $(P<0.001)$ and $20 \mathrm{mg} / \mathrm{kg}$ $(P<0.001)]$ administration significantly attenuated the elevated plasma corticosterone levels in ethanol-withdrawn rats $[\mathrm{F}(4,29)=16.20 ; P<$ $0.001]$.

In addition, ELISA analysis revealed a significant rise in the levels of ACTH follows ethanol withdrawal $(\mathrm{t}=4.72, \mathrm{df}=10, P<0.001$; unpaired $\mathrm{t}$ test). Treatment withaferin A $[10(P<0.05)$ and $20 \mathrm{mg} / \mathrm{kg}(P<0.05)]$ dose dependently reversed the elevated plasma ACTH levels as compare to control rats $[\mathrm{F}(4,29)=5.11 ; P<0.01]$ (Table 3). Administration of withferin A ( $5-20 \mathrm{mg} / \mathrm{kg}$, ip), however, did not alter the basal corticosterone as well as ACTH levels in pair-fed animals (data not shown).

\section{DISCUSSION}

The main observations of this study are that withaferin $\mathrm{A}$, an active constituent of WS, has an inhibitory effect on alcohol abstinence signs in rats. In line with the earlier reports, in current findings, we have observed the approximately $9-15 \mathrm{~g} / \mathrm{kg} /$ day up to 15 days, which further produces the physical dependence in rats. ${ }^{29,30}$ In the present study, very high blood ethanol levels $(174.44 \pm 8.15 \mathrm{mg} / \mathrm{dl})$ observed just before ethanol withdrawal indicates an adequate quantity of ethanol consumed $(13.6 \pm 1.3$ to $15.8 \pm 2.1 \mathrm{~g} / \mathrm{kg})$ for the induction of abstinence signs. Pilot studies from our laboratory as well as earlier published studies have demonstrated that ethanol withdrawal displays its peak behavioral and biochemical signs following $24 \mathrm{~h}$ of ethanol withdrawal. As depicted in Table 1, ethanol withdrawal in animal resulted insignificant decline in the blood ethanol concentration. In our study, ethanol abstinence was characterized by increased scores of stereotyped behaviors, motor hyperactivity, behavioral despair and anxiety-like behavior in EPM test. Our previous findings that ethanol withdrawal anxiety ${ }^{18}$ and depression ${ }^{17}$ in rodents support the development of psychological dependence. Negative reinforcement in ethanol withdrawal is one of the potential reason for ethanol dependence and reinstatement. ${ }^{31,32}$ Similarly, dysphoria like the state is very common following the withdrawal of substances of abuse like ethanol, nicotine, and morphine and has been demonstrated in several animal models of depression. ${ }^{33,35}$ This negative emotional state of ethanol withdrawal has been suggested a key factor in the maintenance of ethanol addiction (i.e., alcohol self-administration to prevent withdrawal). ${ }^{36}$

WS has been widely investigated for their diverse pharmacological activities, phytochemically it contains steroidal lactones, alkaloids, flavonoids, tannin etc. Withaferin A, predominantly found in WS known as withanolide. Several publish report acclaimed its different pharmacological activities viz. anti-inflammatory, anti-stress, ${ }^{12,37} \mathrm{immu}$ nomodulatory, ${ }^{10}$ inhibition of cognitive deficits in Alzheimer's disease ${ }^{38}$ and anxiolytic-antidepressant action in rats $^{7}$ without inducing any significant toxicity. In the present study, we evaluated the effects of acute and chronic injections of withaferin $\mathrm{A}$ on the somatic manifestations, anxiety, and depression-like effect of ethanol withdrawal. Our results demonstrate that subchronic withaferin A administration (day 15-21) during ethanol exposure prevented the somatic expression of ethanol withdrawal as revealed by a significant decrease in the most prominent somatic signs of ethanol withdrawal and also prevented the anxiety and depression-like behavior in ethanol-withdrawn rats. However, acute injection of withaferin A 30 min prior withdrawal testing did not influence any of the ethanol withdrawal signs. It is of interest to note that withaferin A (glyco with anolide) has been reported to have both anxiolytic and antidepressant activity in rats, supporting the contention that this bioactive component of WS is the effective mood regulator. ${ }^{7}$
Activation of the hypothalamo-pituitary-adrenocortical axis (HPA) during stress is a well-known phenomenon, an increase in plasma corticosterone in rodents and cortisol in humans have been utilized as markers of withdrawal associated stress and its intensity. ${ }^{39-40}$ Single ethanol withdrawal induces the maladaptive drinking symptoms like anxiety, hyperactivity etc. which have been correlated with the elevated corticotrophin-releasing factor levels. ${ }^{41}$ Interestingly, these maladaptive symptoms of alcohol withdrawal have been reversed. ${ }^{42}$ Therefore the CRF has been proposed as a key mediator in drug and ethanol dependence. ${ }^{43}$ Current reports suggest the neuroadaptative alterations activated by chronic alcohol exposure leads to up-regulation of CRF system. ${ }^{44}$ Importantly, ethanol-withdrawn animals demonstrated a marked elevation in $\mathrm{ACTH}$ and corticosterone levels, which was reversed by withaferin A treatment. It is likely that withaferin A by its interaction with the central stress regulating system might have attenuated ethanol withdrawal syndrome in rats. ${ }^{45}$ However, the role of other proposed biological targets of WS like GABA and opioids receptors needs further investigation. Thus, withaferinA-induced anti-stress effect and stabilization of HPA axis activity could have facilitated the inhibitory effect of withaferin A on ethanol withdrawal syndrome.

In conclusion, this study demonstrated that prolong administration of withaferin A during exposure to ethanol attenuate the ethanol withdrawal-induced somatic hyperexcitability, anxiety, and dysphoria like state in chronically ethanol-exposed animals. These findings strongly support further investigation of withaferin A and other bioactive components of WS in alcohol addiction. The data clearly projects withaferin $\mathrm{A}$ as a new potential therapeutic intervention in alcohol abuse associated complications.

\section{CONFLICT OF INTEREST}

The authors have no conflict of interest.

\section{ABBREVIATIONS}

WS: Withania somnifera; HPA: Hypothalamic Pituitary adrenal; EPM: Elevated Plus Maze; FST: Forced Swim Test; EAS: Ethanol Abstinence Score; ACTH: Adreno-Corticotropic Hormone.

\section{ACKNOWLEDGEMENT}

The work was funded under the institutional research grant.

\section{REFERENCES}

1. Campos J, Roca L, Gude F, Gonzalez-Quintela A. Long-term mortality of patients admitted to the hospital with alcohol withdrawal syndrome. Alcoho Clin Exp. Res 2011;35(6):1180-6.

2. Uzbay IT, Kayir H, Celik T, Yuksel N. Acute and chronic tianeptine treatments attenuate ethanol withdrawal syndrome in rats. Prog. Neuropsychopharmacol. Biol Psychiatry. 2006;30(3):478-85.

3. Malcolm RJ. GABA systems, benzodiazepines, and substance dependence J Clin Psychiatry. 2003;64(3):36-40.

4. Leggio L, Kenna GA, Swift RM. New developments for the pharmacological treatment of alcohol withdrawal syndrome. A focus on non-benzodiazepine GABAergic medications. Prog Neuropsychopharmacol Biol Psychiatry. 2008;32(5):1106-17.

5. Bhattacharya A, Ghosal S, Bhattacharya SK. Antioxidant effect of Withania somnifera glycowithanolides in chronic footshock stress-induced perturbations of oxidative free radical scavenging enzymes and lipid peroxidation in rat frontal cortex and striatum. J Ethnopharmacol. 2001;74(1):1-6.

6. Bhattacharya SK, Muruganandam AV. Adaptogenic activity of Withania somnifera: an experimental study using a rat model of chronic stress. Pharmacol Biochem Behav. 2003;75(3):547-55.

7. Bhattacharya SK, Bhattacharya A, Sairam K, Ghosal, S Anxiolytic-antidepressant activity of Withania somniferaglycowithanolides: an experimental study. Phytomedicine. 2000;7(6):463-9.

8. Ahmad M, Saleem S, Ahmad AS, Ansari MA, Yousuf S, Hoda MN, Islam F Neuroprotective effects of Withania somnifera on 6-hydroxydopamine induced Parkinsonism in rats. Hum Exp Toxicol. 2005;24(3):137-47. 
9. Owais M, Sharad KS, Shehbaz A, Saleemuddin M. Antibacterial efficacy of Withania somnifera (ashwagandha) an indigenous medicinal plant against experimental murine salmonellosis. Phytomedicine. 2005;12(3):229-35.

10. Rasool M, Varalakshmi P. Immunomodulatory role of Withania somnifera root powder on experimental induced inflammation: An in vivo and in vitro study. Vascul Pharmacol. 2006;44(6):406-10.

11. Yang Z, Garcia A, Xu S, Powell DR, Vertino PM, Singh S, Marcus Al. Withania somnifera root extract inhibits mammary cancer metastasis and epithelial to mesenchymal transition. PLoS One. 2013;8(9):e75069.

12. Gupta A, Singh S. Evaluation of anti-inflammatory effect of Withania somnifera root on collagen-induced arthritis in rats. Pharm Biol. 2014;52(3):308-20.

13. Ruiu S, Longoni R, Spina L, Orrù A, Cottiglia F, Collu M, Kasture S, Acquas E. Withania somnifera prevents acquisition and expression of morphine-elicited conditioned place preference. Behav Pharmacol. 2013;24(2):133-43.

14. Spina L, Longoni R, Rosas M, Collu M, Peana AT, Espa E, Kasture S, Cotti E, Acquas E. Withania somnifera Dunal (Indian ginseng) impairs acquisition and expression of ethanol-elicited conditioned place preference and conditioned place aversion. J Psychopharmacol. 2015;29(11):1191-9.

15. Peana AT, Muggironi G, Spina L, Rosas M, Kasture SB, Cotti E, Acquas E. Effects of Withania somnifera on oral ethanol self-administration in rats. Behav Pharmacol. 2014;25(7):618-28.

16. Gupta GL, Rana AC. Effect of Withania somnifera Dunal in ethanol-induced anxiolysis and withdrawal anxiety in rats. Indian J Exp Biol. 2008;46(6):470-5.

17. Kokare DM, Singru PS, Dandekar MP, Chopde CT, Subhedar NK. Involvement of alpha-melanocyte stimulating hormone $(\alpha-\mathrm{MSH})$ in differential ethanol exposure and withdrawal related depression in rat: neuroanatomical-behavioral correlates. Brain Res. 2008;1216:53-67.

18. Taksande BG, Kotagale NR, Patel MR, Shelkar GP, Ugale RR, Chopde CT. Agmatine, an endogenous imidazoline receptor ligand modulates ethanol anxiolysis and withdrawal anxiety in rats. Eur J Pharmacol. 2010;637(1-3):89-101.

19. Uzbay IT, Erden BF. Attenuation of ethanol withdrawal signs by high doses of L-arginine in rats. Alcohol Alcohol. 2003;38(3):213-8.

20. Macey DJ, Schulteis G, Heinrichs SC, Koob GF. Time-dependent quantifiable withdrawal from ethanol in the rat: effect of method of dependence induction. Alcohol. 1996;13(2):163-70.

21. Kokare DM, Chopde CT, Subhedar NK. Participation of alpha-melanocyte stimulating hormone in ethanol-induced anxiolysis and withdrawal anxiety in rats Neuropharmacology. 2006;51(3):536-45

22. Uzbay IT, Erden BF, Tapanyigit EE, Kayaalp SO. Nitric oxide synthase inhibition attenuates signs of ethanol withdrawal in rats. Life Sci. 1997;61(22):2197-209.

23. Porsolt RD, Bertin A, Jalfre M. Behavioural despair in mice: a primary screening test for antidepressants. Arch Int Pharmacodynamic Theory. 1977;229(2):327-36

24. Goyal SN, Kokare DM, Chopde CT, Subhedar NK. Alpha-melanocyte stimulating hormone antagonizes antidepressant-like effect of neuropeptide $Y$ in Porsolt's test in rats. Pharmacol Biochem Behav. 2006;85(2):369-77.

25. Zapata A, Gonzales RA, Shippenberg TS. Repeated ethanol intoxication induces behavioural sensitization in the absence of a sensitized accumbens dopamine response in C57BL/6J and DBA/2J Mice. Neuropsychopharmacol. 2006:31(2):396-405.

26. Sheikh N, Ahmad A, Siripurapu K, KuchibhotlaV, Singh S, Palit G. Effect of Bacopa monniera on stress induced changes in plasma corticosterone and brain monoamines in rats. J Ethnopharmacol. 2007;111(3):671-2.

27. Taksande BG, Faldu DS, Dixit MP, Sakaria JN, Aglawe MM, Umekar MJ, Kotagale NR. Agmatine attenuates chronic unpredictable mild stress inducedbehavioral alteration in mice. Eur J Pharmacol. 2013;720(1-3):115-20.

28. Makrigiannakis A, Semmler M, Briese V, Eckerle H, Minas V, Mylonas I, Friese K,
Jeschke U. Maternal serum corticotropin-releasing hormone and ACTH levels as predictive markers of premature labor. Int J Gynaecol Obstet. 2007:97(2):115-9.

29. Majchrowicz E. Induction of physical dependence upon ethanol and the as sociated behavioral changes in rats. Psychopharmacologia. 1975;43(3):245-54.

30. Uzbay IT, Yesilyurt O, Celik T, Ergün $\mathrm{H}$, Isimer A. Effects of agmatine on ethanol withdrawal syndrome in rats. Behav Brain Res. 2000;107(1-2):153-9.

31. Roelofs SM. Hyperventilation, anxiety, craving for alcohol: a subacute alcohol withdrawal syndrome. Alcohol. 1985;2(3):501-5.

32. Zhang Z, Morse AC, Koob GF, Schulteis G. Dose- and time-dependent expression of anxiety-like behavior in the elevated plus-maze during withdrawal from acute and repeated intermittent ethanol intoxication in rats. Alcohol Clin Exp Res. 2007;31(11):1811-19.

33. Cryan JF, Hoyer D, Markou A. Withdrawal from chronic amphetamine induces depressive-like behavioral effects in rodents. Biol Psychiatry. 2003;54(1):49-58

34. Rothwell PE, Thomas MJ, Gewirtz JC. Distinct profiles of anxiety and dysphoria during spontaneous withdrawal from acute morphine exposure. Neuropsychopharmacology. 2009;34(10):2285-95

35. Frankowska M, Golda A, Wydra K, Gruca P, Papp M, Filip M. Effects of imipramine or $\mathrm{GABA}(\mathrm{B})$ receptor ligands on the immobility, swimming and climbing in the forced swim test in rats following discontinuation of cocaine self-administration. Eur J Pharmacol. 2010;627(1-3):142-9.

36. Koob GF. Corticotropin-releasing factor, neuroplasticity (sensitization), and alcoholism. Proc Natl Acad Sci USA. 2008:105(26):8809-10.

37. Bhattacharya SK, Muruganandam AV. Adaptogenic activity of Withania somnifera: an experimental study using a rat model of chronic stress. Pharmacol Biochem Behav. 2003;75(3):547-55.

38. Sehgal N, Gupta A, Valli RK, Joshi SD, Mills JT, Hamel E, Khanna P, Jain SC Thakur SS, Ravindranath V. Withania somnifera reverses Alzheimer's disease pathology by enhancing low-density lipoprotein receptor-related protein in liver. Proc Natl Acad Sci USA. 2012:109(9):3510-5.

39. Munro CA, Oswald LM, Weerts EM, McCaul ME, Wand GS. Hormone responses to social stress in abstinent alcohol-dependent subjects and social drinkers with no history of alcohol dependence. Alcohol Clin Exp Res. 2005;29(7):1133-8.

40. Borlikova GG, Le Merrer J, Stephens DN. Previous experience of ethanol withdrawal increases withdrawal-induced c-fos expression in limbic areas, but not withdrawal-induced anxiety and prevents withdrawal-induced elevations in plasma corticosterone. Psychopharmacology (Berl). 2006;185(2):188-200.

41. Becker HC. Effects of alcohol dependence and withdrawal on stress responsiveness and alcohol consumption. Alcohol Res. 2012;34(4):448-58.

42. Funk CK, Zorrilla EP, Lee MJ, Rice KC, Koob GF. Corticotropin-releasing factor 1 antagonists selectively reduce ethanol self-administration in ethanol-dependent rats. Biol Psychiatry. 2007;61(1):78-86.

43. Heilig M, Koob GF. A key role for corticotropin-releasing factor in alcohol dependence. Trends Neurosci. 2007;30(8):399-06.

44. Sommer WH, Rimondini R, Hansson AC, Hipskind PA, Gehlert DR, Barr CS Heilig MA. Upregulation of voluntary alcohol intake, behavioral sensitivity to stress, and amygdala crhr1 expression following a history of dependence. Bio Psychiatry. 2008;63(2):139-45.

45. Rasmussen DD, Boldt BM, Bryant CA, Mitton DR, Larsen SA, Wilkinson CW Chronic daily ethanol and withdrawal: Long-term changes in the hypothalamopituitary-adrenal axis. Alcohol Clin Exp Res. 2000;24(12):1836-49.

\section{GRAPHICAL ABSTRACT}

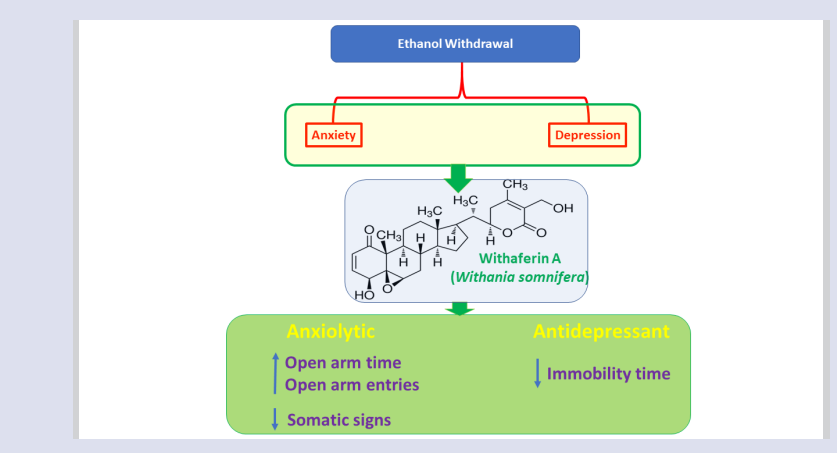

\section{SUMMARY}

- Alcoholism and withdrawal of its chronic intake are serious social and medical problems. There is no appropriate drug therapy which helps the patients to overcoming the withdrawal symptoms. Present study investigated the beneficial effects of withaferin A during ethanol dependence and withdrawal, hence projected new therapeutic drug molecule for the effective management of alcoholism.

Cite this article: Kotagale NR, Kedia A, Gite R, Rahmatkar SN, Gawande DY, Umekar MJ, Taksande BG. Withaferin A attenuates Alcohol Abstinence Signs in Rats. Pharmacog J. 2018;10(6):1190-5. 